\title{
Accurate Prediction of Voltage Gain of the LLC Resonant Converter for EV battery Charge Applications
}

\author{
$1 *$ Sevilay Çetin \\ ${ }^{1}$ Pamukkale University, Denizli, Turkey
}

\begin{abstract}
This work presents detailed analysis of LLC resonant converter to accurately predcit the voltage gain of the converter. Nowadays, Lithium-ion battery cells are mostly preferred for on-board electrical vehicle (EV) battery chargers due to their high power density. This results in wide range output voltage regulation for battery charger. The output voltage regulation of LLC resonant converter is provided by the changing of switching frequency. The conventional first harmonic approximation (FHA) method is usually used for resonant converters and it is not reliable when switching frequency changes in wide range, especiaaly below resonance region. Therefore, the objective of this paper is accurate prediction of the voltage gain characteristic for LLC resonant converter used in EV battery charge applications. The detailed theoretical anlysis of the LLC resonant converter is presented and the presented analysis is compared with a simulation study with $2.7 \mathrm{~kW}$ output power and $250 \mathrm{~V}-450 \mathrm{~V}$ output voltage range. Key words: Agricultural tractors, Rod clutch, Shuttle chain locking mechanism
\end{abstract}

\section{Introduction}

Nowadays, the use of electrical vehicle (EV) increases greatly due to benefits in air pollution and economy. The on-board battery charger design provides flexibility to the end-user allowing charge vehicle's battery from any available power point [1]. However, on board charger design can increase the EV's volume and weight, this also reduces the performance of vehicle [2]-[4]. Therefore, high power density and low weight battery charger design is important in EV technology to reduce costs [5], [6].

The lithium-ion battery chargers are very common in order to obtain high power density because they have higher current and voltage rates compared to other battery structure [2], [7], [8]. Thus, battery charger should provide wide range output voltage and current regulation.

A battery charger composed of two part : one of them AC-DC conversion stage which has power factor correction function and the other is DC-DC battery voltage regulation stage [1], [2], [9], [10]. This paper is focused on the second stage. The second is regulates the output voltage of first stage which has second harmonic of line voltage. The soft switching converters are very popular to obtain high power density and high efficiency, with the operation at high switching frequencies [1], [9]-[11].

The resonant converters naturally work with soft switching, they don't require additional circuit component. Their soft switching operation are not depend on the load condition. However, their output voltage regulation is provided with frequency variation and this well-known disadvantage of resonant converters. Because frequency change limits the design optimization of the magnetic components of the converter. The LLC resonant converter has narrow switching frequency range compared to the other resonant converters (series, parallel and LCC). The LLC resonant converter doesn't require an output filter inductor so it has advantage to increase power density [12]. Therefore, in this work, the LLC resonant converter topology is selected for the second stage of EV battery charger design.

*Corresponding author: Address: Pamukkale University, Denizli, Turkey 
The first harmonic approximation (FHA) method is usually used to extract the dc gain of LLC resonant converter. The analysis and design procedure of the converter are discussed in the literature based on FHA [13]-[16]. However FHA is produces valid result at and above resonance frequency [17] and it produces errors below resonance frequency region [10], [11].

In [18] and [19], the gain of the LLC resonant converter is extracted based on steady state analysis but it is not presented closed-form solution due to the complexity of nonlinear equations. In [20], the voltage gain of the LLC resonant converter is presented based on time domain analysis below resonance frequency. It presented closed form statement and more acceptable results compared to FHA.

This work evaluates the accurate voltage gain characteristic of the LLC resonant converter for EV battery charger applications. The converter is analyzed based on [20] during boost mode operation. The FHA method is applied at and above resonance operation during buck mode operation. Then, a simulation study is presented to evaluate analytical results. The comparison shows that simulation results and analytical results are in good match.

\section{Mode analysis of LLC Resonant Converter}

The circuit scheme of the LLC resonant converter is shown in Fig. 1. The input voltage Vi is usually obtained from front end AC-DC converter for battery charger applications. Vo represents the battery charge voltage. S1-S4 are the primary MOSFETs operating ZVS turn-on, naturally. $D_{R 1}-D_{R 4}$ are the rectifier diodes producing DC output voltage. $L_{m}$ is the mutual inductance of the power transformer, $\mathrm{L}_{\mathrm{s}}$ is the resonant inductor, which can be realized simply by introducing an air gap in the power transformer. $\mathrm{C}_{\mathrm{r}}$ is the resonant capacitor.

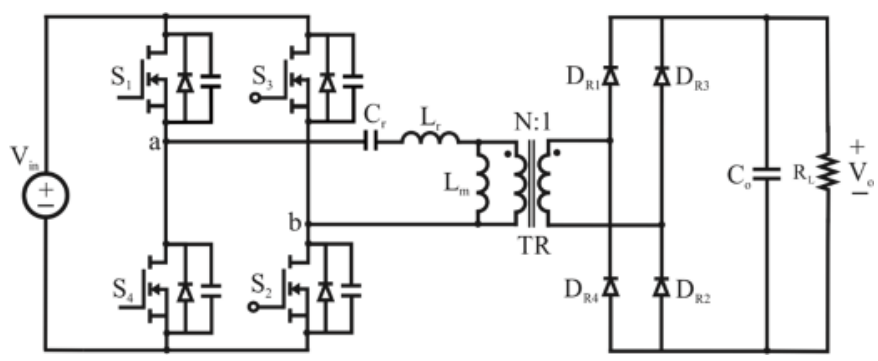

Fig. 1 The circuit scheme of the LLC resonant converter.

In the operation of the converter, $\mathrm{S}_{1}-\mathrm{S}_{2}$ and $\mathrm{S}_{3}-\mathrm{S}_{4}$ MOSFET pairs conduct with $50 \%$ duty ratio in a switching period to produce symmetrical voltage across the primary side of the transformer. The well-known voltage gain characteristic of the converter based on first harmonic approximation (FHA) is given in Fig. 2 in order to define operation modes.

In Region 1, converter works with buck operation and the series resonant converter behavior is dominated with the resonance occurred between $L_{r}$ and $C_{r}$. This operation is provided above switching frequency and so converter always works with inductive characteristic in this region. Thus, primary MOSFETs turn on with zero voltage switching (ZVS). 
In Region 2, converter works with boost operation and the operation is more complex than Region 1. The series resonance and parallel resonance operation characteristics take place according to load condition. In this region, there should be a boundary between inductive and capacitive operation to provide ZVS turn-on for primary MOSFETs.

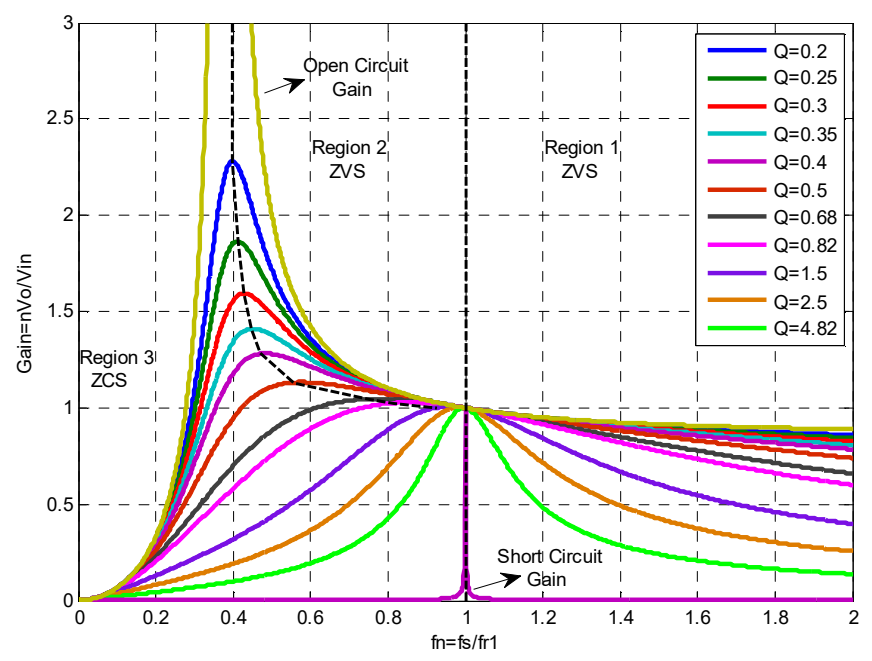

Fig. 2. The typical de voltage gain characteristics of LLC resonant converter based on FHA.

\section{A. Analysis of Region 2:}

In this region, LLC resonant converter operates to increase output voltage. The key waveforms and equivalent circuit belong to operation modes are given in Fig. 3 and Fig. 4, respectively. In the other half switching period, converter works with same principle with inverse voltage applied to the resonant tank. Therefore, only one switching period is took into consideration in this section. In the analysis, it is supposed that all semiconductors are ideal, the output filter capacitor is large enough and so the output voltage is constant.

Mode 1 ( $\left.\mathbf{t}_{0}-\mathbf{t}_{2}\right)$ : Fig. 4(a) shows equivalent circuit of this operation. $\mathrm{S}_{1}$ and $\mathrm{S}_{2}$ MOSFETs are turned on at $\mathrm{t}=\mathrm{t}_{0}$ and square wave input voltage is applied to the resonant tank composed of $\mathrm{L}_{\mathrm{r}}-\mathrm{C}_{\mathrm{r}^{-}}$ $\mathrm{L}_{\mathrm{m}}$. Thus, a resonance occurs between $\mathrm{L}_{r}-\mathrm{C}_{\mathrm{r}}$ and $\mathrm{i}_{\mathrm{Lr}}$ current starts to increase with a negative initial value. At $t=t_{1}, i_{L r}$ reaches zero and continue to increase with resonance. The magnetizing current, $i_{\mathrm{Lm}}$, increases linearly since the voltage across the magnetizing current is $\mathrm{NV}_{\mathrm{o}}$, which is respected from secondary side. The frequency of current and voltage variation is equal to the first resonance frequency, $f_{r 1}$. The equations belong to this mode can be written as follows:

$$
\begin{aligned}
& i_{L r}(t)=\frac{V_{i n}-N V_{o}-V_{C r 0}}{Z_{r 1}} \sin \omega_{r 1} t+I_{L r 0} \cos \omega_{r 1} t \\
& i_{L m}(t)=\frac{N V_{o}}{L_{m}} t+I_{L m 0}
\end{aligned}
$$


$i_{S 1}(t)=i_{L r}(t)$

$v_{C r}(t)=V_{\text {in }}-N V_{o}+\left(V_{C r 0}-V_{\text {in }}+N V_{o}\right) \cos \omega_{r 1} t$

$+I_{L r 0} Z_{r 1} \sin \omega_{r 1} t$

$v_{C r}(t)=V_{\text {in }}-N V_{o}+\left(V_{C r 0}-V_{\text {in }}+N V_{o}\right) \cos \omega_{r 1} t$

$+I_{L r 0} Z_{r 1} \sin \omega_{r 1} t$

$i_{D R 1, D R 2}(t)=N\left[i_{L r}(t)-i_{L m}(t)\right]$

Above, $\mathrm{Z}_{\mathrm{r} 1}, \omega_{\mathrm{r} 1}$ are defined as follows:

$\omega_{r 1}=\frac{1}{\sqrt{L_{r} C_{r}}}$
$Z_{r 1}=\sqrt{\frac{L_{r}}{C_{r}}}$

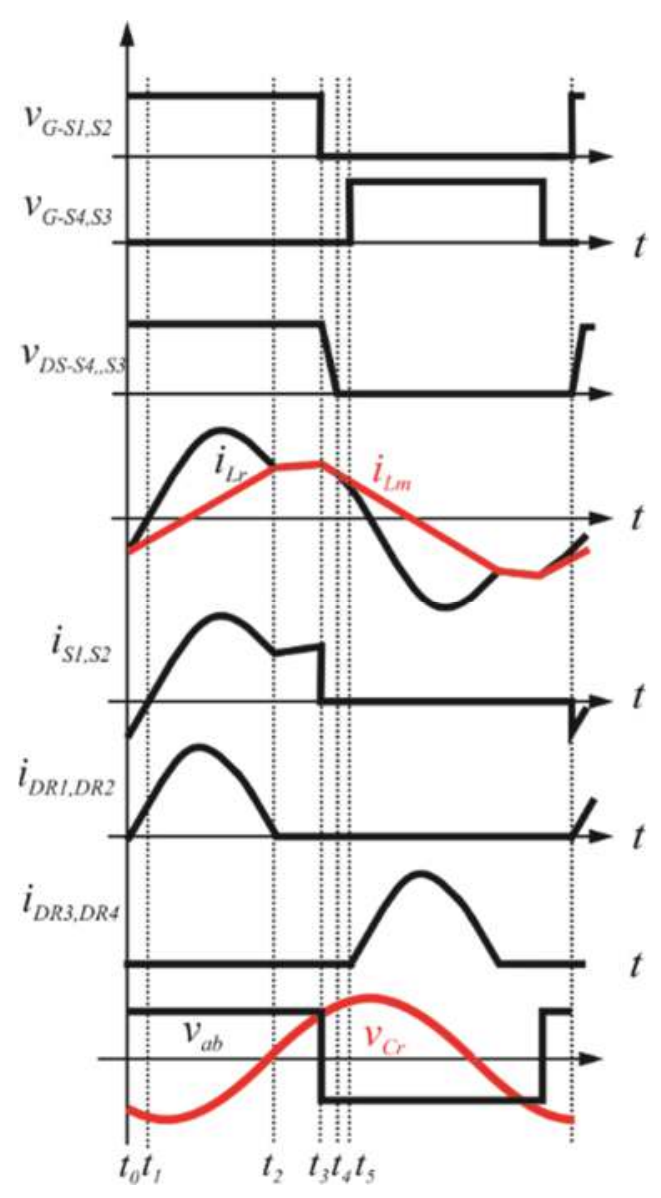

Fig. 3. The key waveforms of LLC resonant converter in Region 2. 


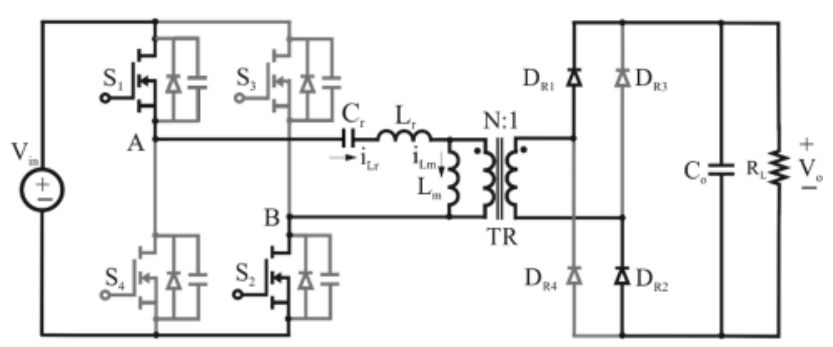

$t_{0}-t_{2}$

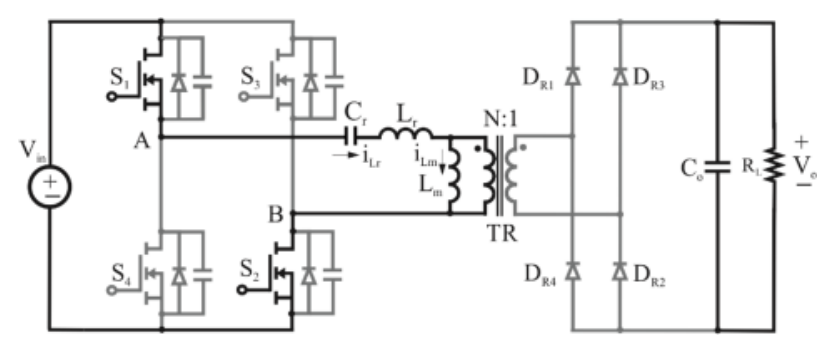

$t_{2}-t_{3}$

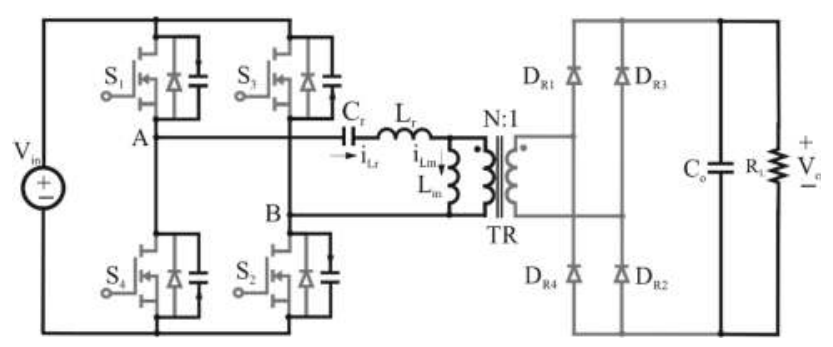

$t_{3}-t_{4}$

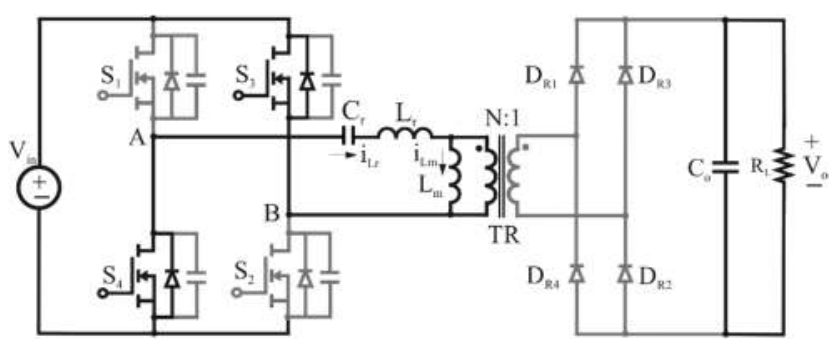

$t_{4}-t_{5}$

Fig. 4 The equivalent circuit of LLC resonant DC-DC converter in Region 2.

At the secondary side, $D_{R}$ and $D_{R 2}$ conduct on to produce dc output voltage, $V_{0}$. This mode ends at $\mathrm{t}=\mathrm{t}_{2}$ when the current of rectifier diodes reaches zero. Thus, in the half of $f_{r 1}, D_{R} 1$ and $D_{R 2}$ turn on and transfer the energy to the output. Thus, it can be defined that $\mathrm{t}_{2}=\pi / \omega_{\mathrm{r} 1}$.

Above, $\mathrm{I}_{\mathrm{Lr} 0}=\mathrm{I}_{\mathrm{Lm} 0}, \mathrm{I}_{\mathrm{Lr} 2}=\mathrm{I}_{\mathrm{Lm} 2}, \mathrm{I}_{\mathrm{Lr} 0}=-\mathrm{I}_{\mathrm{Lr} 2}$ and $\mathrm{I}_{\mathrm{Lr} 0}=-\mathrm{I}_{\mathrm{Lr} 2}$. $\mathrm{I}_{\mathrm{Lr} 2}$ is equal to the maximum value of the magnetizing current and it can be defined by: 
$I_{L r 2}=I_{L m-\max }=\frac{N V_{o}}{L_{m}} \times \frac{\pi}{2 \omega_{r 1}}$

Similarly, $\mathrm{V}_{\mathrm{Cr} 0}=-\mathrm{V}_{\mathrm{Cr} 3}$ and for $\mathrm{t}_{2}=\pi / \omega_{\mathrm{r} 1} \mathrm{~V}_{\mathrm{Cr}}$ can be obtained as follows:

$V_{C r 2}=-V_{C r 0}+2\left(V_{i n}-N V_{0}\right)$.

Mode $2\left(\mathbf{t}_{2}-\mathbf{t}_{3}\right)$ : The equivalent circuit belong to this operation is given in Fig. 4 . The voltage across the magnetizing inductance $\mathrm{NV}_{\mathrm{o}}$ is removed when the rectifier diodes are turned-off and another resonance starts between $\mathrm{L}_{r}-\mathrm{C}_{r}-\mathrm{L}_{\mathrm{m}}$. In this operation there is no energy transfer to the output and $i_{L r}$ current flows at the primary side freely. The current and voltage equations belong to this mode can be written as below:

$$
\begin{aligned}
& i_{L r}(t)=i_{L m}(t)=\frac{V_{i n}-V_{C r 2}}{Z_{r 2}} \sin \left(\omega_{r 2}\left(t-t_{3}\right)\right) \\
& +I_{L r 2} \cos \left(\omega_{r 2}\left(t-t_{3}\right)\right) \\
& i_{L m}(t)=i_{L r}(t) \\
& v_{C r}(t)=V_{i n}+\left(V_{C r 2}-V_{i n}\right) \cos \left(\omega_{r 2}\left(t-t_{3}\right)\right) \\
& +I_{L r 2} Z_{r 2} \sin \left(\omega_{r 2}\left(t-t_{3}\right)\right) \\
& i_{S 1}(t)=i_{L r}(t) \\
& i_{D R 1, D R 2}(t)=0
\end{aligned}
$$

Above, $Z_{\mathrm{r} 2}$ and $\omega_{\mathrm{r} 2}$, represent the resonance impedance and resonance radial frequency, respectively. They can be defined as follows:

$$
\begin{aligned}
& \omega_{r 2}=\frac{1}{\sqrt{\left(L_{r}+L_{m}\right) C_{r}}} \\
& Z_{r 2}=\sqrt{\frac{\left(L_{r}+L_{m}\right)}{C_{r}}}
\end{aligned}
$$

If dead time is neglected, $\mathrm{S}_{1}$ and $\mathrm{S}_{2}$ MOSFETs are turned-off with the peak value of magnetizing current at $\mathrm{t}=\mathrm{t}_{3}$, approximately at the end of one half of the switching period and this mode is completed.

The resonant capacitor voltage for $\mathrm{t}=\mathrm{t}_{3}$ is obtained as follows:

$$
v_{C r 3}=-V_{C r 0}=V_{i n}+\left(V_{C r 2}-V_{i n}\right) \cos \alpha+I_{L r 2} Z_{r 2} \sin \alpha
$$

Where $\alpha$ is radial distance between $t_{3}-t_{2}$ and defined as follows: 
$\alpha=\omega_{r 2}\left(t_{3}-t_{2}\right)$

The resonant capacitor voltage for $\mathrm{t}=\mathrm{t}_{0}$ after rearrangement of (18) can be defined as follows, as given in [20]:

$V_{C r 0}=\frac{1}{\cos \alpha-1}\left[\begin{array}{l}\left(V_{i n}-2 N V_{0}\right) \cos \alpha \\ +Z_{r 2} \frac{N V_{0} \pi}{2 L_{m} \omega_{r}} \sin \alpha+V_{i n}\end{array}\right]$

Mode 3 (t $\left.\mathbf{t}_{3}-\mathbf{t}_{5}\right)$ : The equivalent circuit diagrams belong to this operation are given in Fig. 8(c) and Fig. $8(\mathrm{~d})$. This mode can also be defined as dead time, $t_{\text {dead. }}$ In this operation, magnetizing current charge the parasitic capacitors of $\mathrm{S}_{1}$ and $\mathrm{S}_{2}$ MOSFETs while discharge the parasitic capacitors of $\mathrm{S}_{3}$ and $\mathrm{S}_{4}$ MOSFETs. Thus, $\mathrm{S}_{3}$ and $\mathrm{S}_{4}$ MOSFETs are turned-on with ZVS and following equation can be written for one leg of the converter:

$C_{S 1} \frac{V_{\text {in }}}{t_{\text {dead }}}+C_{S 4} \frac{V_{\text {in }}}{t_{\text {dead }}}=I_{L r 3}=I_{L m 3}$

Above, $C_{S 1}$ and $C_{S 4}$ are the parasitic capacitors of $S_{1}$ and $S_{4}$ MOSFETs. $I_{L m 3}$ is the maximum value of the magnetizing current.

The antiparallel diode of S3 and S4 MOSFETs are turned-on at $\mathrm{t}=\mathrm{t}_{4}$, when the voltage of $\mathrm{C}_{\mathrm{S} 3}$ and $\mathrm{C}_{\mathrm{S} 4}$ parasitic capacitor reaches zero and the voltage of $\mathrm{C}_{\mathrm{S} 1}$ and $\mathrm{C}_{\mathrm{S} 2}$ reaches to $\mathrm{V}_{\text {in }}$. The conduction of antiparallel diode of $\mathrm{S}_{3}$ and $\mathrm{S}_{4}$ MOSFETs provides ZVS turn-on for S3 and S4. Thus, one half switching period is completed.

In Region 2, average output current is defined as follows:

$I_{o}=\frac{1}{T_{s}} \int_{0}^{t_{2}} N\left[i_{L r}(t)-i_{L m}(t)\right] d t$

After solving and rearrangement of (18), the output voltage of the LLC resonant converter can be defined as below, as given in [20]:

$V_{o}=\frac{2 V_{i n}}{(1-\cos \alpha) N}\left[\begin{array}{l}\frac{\pi}{2 R_{L}{ }^{\prime} C_{r} \omega_{s}}+\frac{\sqrt{L_{r}+L_{m}} \pi \sqrt{L_{r}} \sin \alpha}{2 L_{m}(\cos \alpha-1)} \\ -\frac{2 \cos \alpha}{\cos \alpha-1}+1\end{array}\right]^{-1}$

Given analysis above for Region 2, $\mathrm{f}_{\mathrm{r} 2}$ defines the boundary between capacitive and inductive region. Thus, reactive impedance is removed and only resistive effect takes place at $f_{r 2}$. Therefore, the boundary between inductive and capacitive region, ZVS turn-on boundary, can be obtained eliminating sinus component in (23) as follows: 
$V_{o-Z V S}=\frac{2 V_{i n}}{(1-\cos \beta) \times N} \times\left[\begin{array}{l}\frac{\pi}{2 C_{r} R_{L}^{\prime} \omega_{s}} \\ -\frac{2 \cos \beta}{\cos \beta-1}+1\end{array}\right]^{-1}$

The no load voltage gain can be defined for $\mathrm{R}_{\mathrm{L}}{ }^{\prime}=\infty$ in $(23)$ and it is obtained as

$$
V_{O-N L}=\frac{2 V_{i n}}{(1-\cos \beta) \times N} \times\left[\begin{array}{l}
\frac{\pi L_{r} \sqrt{L_{m}+L_{r}}}{2 L_{m} \sqrt{L_{r}}} \times \frac{\sin \beta}{\cos \beta-1} \\
-\frac{2 \cos \beta}{\cos \beta-1}+1
\end{array}\right]^{-1} .
$$

In order to operation with ZVS turn-on in Region, boundary for frequency regulation can be defined as below:

$$
f_{r 2}<f_{s w}<f_{r 1}
$$

Where, $f_{r 1}$ is the first resonance frequency and $f_{r 2}$ is the second resonance frequency defined as follows:

$f_{r 1}=\frac{1}{2 \pi \sqrt{L_{r} C_{r}}}$

$f_{r 2}=\frac{1}{2 \pi \sqrt{\left(L_{m}+L_{r}\right) C_{r}}}$.

B. Analysis of Region 1:

The FHA method gives reliable results at and above $f_{r 1}$ [17] so this method is used for the analysis of Region 1. The used key waveforms and the equivalent circuit model for the analysis of Region 1 is given in Fig. 5.

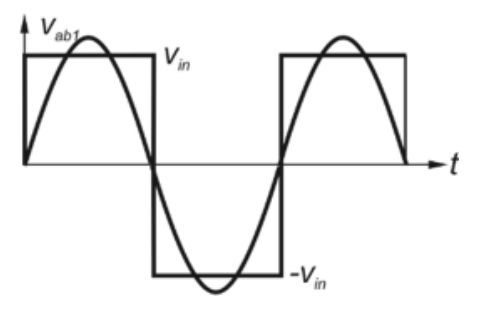

(a)

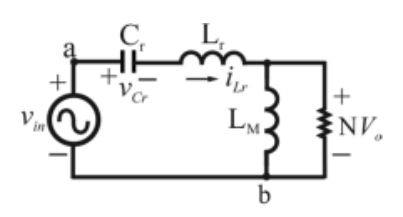


(b)

Fig. 5. The key waveforms (a) and AC equivalent circuit model (b) of LLC resonant converter based on FHA.

The positive input voltage is applied to the resonant tank by the conduction of $\mathrm{S}_{1}$ and $\mathrm{S}_{2}$ MOSFETs. Thus, the obtained current and waveforms can be written as follows:

$i_{L r}(t)=I_{L r-\max } \sin \left(2 \pi f_{r 1} t-\varphi_{1}\right)$

$v_{C r}(t)=V_{\text {in }}-N V_{0}-I_{L r-\max } Z_{r 1} \cos \left(2 \pi f_{r 1} t-\varphi_{1}\right)$

Above, $\mathrm{I}_{\mathrm{Lr}-\mathrm{max}}$ defines the maximum resonant current and $\varphi_{1}$ is the phase angle. They can be defined, respectively as below:

$I_{L r-\max }=\frac{V_{i n}-N V_{o}-V_{C r 0}}{Z_{r 1}}$

$\varphi_{1}=\sin ^{-1} \frac{N V_{0}}{4 L_{m} I_{L r \max } f_{r 1}}$

The voltage gain of LLC resonant converter based on FHA is given as below [18]

$G_{D C}=\frac{V_{o}}{V_{i n}}=\frac{1}{N} \cdot \frac{1}{1+\frac{L_{r}}{L_{m}}\left(1-\frac{f_{r 1}{ }^{2}}{f_{s w}{ }^{2}}\right)+j Q\left(\frac{f_{s w}}{f_{r 1}}-\frac{f_{r 1}}{f_{s w}}\right)}$

Where, $\mathrm{f}_{\mathrm{sw}}$ is the switching frequency, $\mathrm{Q}$ is the quality factor and $\mathrm{R}_{\mathrm{e}}$ is the equivalent $\mathrm{AC}$ resistance reflected to the primary side defined as below:

$$
\begin{aligned}
& Q=\frac{1}{R_{e}} \sqrt{\frac{L_{r}}{C_{r}}} \\
& R_{e}=\frac{8}{\pi^{2}} N^{2} R_{L} .
\end{aligned}
$$

In this region, LLC resonant converter always works with inductive characteristic. Therefore, there is no boundary limitation for ZVS turn-on of primary MOSFETs as happens in Region 2.

\section{Validation of Analytical Analysis by Simulation Results}

In order to validate presented analysis a simulation study is performed. The value of the used components are given in Table 1. 
The analytical output voltage of the LLC resonant converter is extracted by MATLAB and given in Fig. 6 for different load condition. The desired output voltage regulation is provided with switching frequency changing between $110 \mathrm{kHz}$ and $200 \mathrm{kHz}$.

The output voltage values obtained from analytical and simulated results as function of load condition are summarized and compared in Table 2. In addition, the switching frequency comparison as function of the output voltage with constant load is given in Table 3. According to comparison results given in Table 2 and Table 3, analytical and simulation results are in good match with each other.

TABLE 1:THE USED COMPONENTS IN ANALYTICAL AND SIMULATIO
\begin{tabular}{|c|c|}
\hline Components & Values \\
\hline $\mathrm{L}_{\mathrm{M}}$ & $26 \mu \mathrm{F}$ \\
\hline $\mathrm{L}_{\mathrm{r}}$ & $24 \mathrm{nF}$ \\
\hline $\mathrm{C}_{\mathrm{r}}$ & $2700 \mathrm{~W}$ \\
\hline $\mathrm{P}_{\mathrm{o}}$ & $380 \mathrm{~V}-420 \mathrm{~V}$ \\
\hline $\mathrm{V}_{\mathrm{in}}$ & $250-450 \mathrm{~V}$ \\
\hline $\mathrm{V}_{\mathrm{o}}$ & $110-200 \mathrm{kHz}$ \\
\hline $\mathrm{f}_{\mathrm{sw}}$ & $200 \mathrm{kHz}$ \\
\hline $\mathrm{f}_{\mathrm{r} 1}$ & $\mathrm{~N}: 15 / 9$ \\
\hline $\mathrm{TR}$ & \\
\hline
\end{tabular}

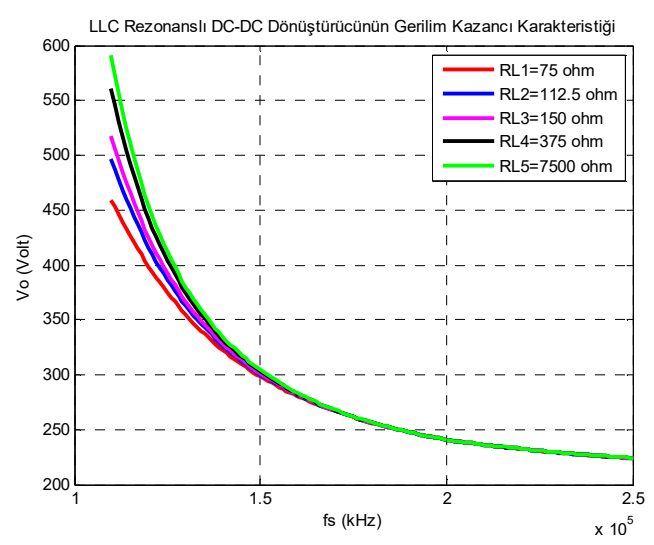

Fig. 6. The analytical output voltage of LLC resonant converter as function of switching frequency. 
TABLE 2:COMPARISON OF OUTPUT VOLTAGE OBTAINED FROM ANALYTICAL AND SIMULATION RESUlTS

\begin{tabular}{|c|c|c|c|}
\hline \multirow{2}{*}{ Load } & $\mathrm{f}_{\mathrm{sw}}$ & \multicolumn{2}{|c|}{$\mathrm{V}_{\mathrm{o}}$} \\
\cline { 3 - 4 } & & Simulation & Analytical \\
\hline $\mathrm{R}_{\mathrm{L} 1}=75 \Omega$ & $110 \mathrm{kHz}$ & $448.3 \mathrm{~V}$ & $452.7 \mathrm{~V}$ \\
\hline $\mathrm{R}_{\mathrm{L} 2}=112.5 \Omega$ & $113 \mathrm{kHz}$ & $449.2 \mathrm{~V}$ & $451.9 \mathrm{~V}$ \\
\hline $\mathrm{R}_{\mathrm{L} 3}=150 \Omega$ & $114 \mathrm{kHz}$ & $448.2 \mathrm{~V}$ & $450 \mathrm{~V}$ \\
\hline $\mathrm{R}_{\mathrm{L} 4}=225 \Omega$ & $114 \mathrm{kHz}$ & $451.6 \mathrm{~V}$ & $452.2 \mathrm{~V}$ \\
\hline $\mathrm{R}_{\mathrm{L} 5}=450 \Omega$ & $114 \mathrm{kHz}$ & $452.1 \mathrm{~V}$ & $453.4 \mathrm{~V}$ \\
\hline
\end{tabular}

TABLE 3:COMPARISON OF SWITCHING FREQUENCY AS FunCtion OF THE OUTPUT VOLTAGE With CONSTANT LOAD

\begin{tabular}{|c|c|c|}
\hline \multirow{2}{*}{$\mathrm{V}_{\mathrm{o}}$} & \multicolumn{2}{|c|}{$\mathrm{f}_{\mathrm{sw}}, \mathrm{I}_{\mathrm{o}}=6 \mathrm{~A}$} \\
\cline { 2 - 3 } & Simulation & Analytical \\
\hline $450 \mathrm{~V}$ & $109.8 \mathrm{kHz}$ & $113 \mathrm{kHz}$ \\
\hline $425 \mathrm{~V}$ & $113 \mathrm{kHz}$ & $115 \mathrm{kHz}$ \\
\hline $400 \mathrm{~V}$ & $118 \mathrm{kHz}$ & $116 \mathrm{kHz}$ \\
\hline $375 \mathrm{~V}$ & $121 \mathrm{kHz}$ & $125 \mathrm{kHz}$ \\
\hline $350 \mathrm{~V}$ & $126 \mathrm{kHz}$ & $128 \mathrm{kHz}$ \\
\hline $325 \mathrm{~V}$ & $134 \mathrm{kHz}$ & $137 \mathrm{kHz}$ \\
\hline $300 \mathrm{~V}$ & $144 \mathrm{kHz}$ & $148 \mathrm{kHz}$ \\
\hline $275 \mathrm{~V}$ & $159 \mathrm{kHz}$ & $162 \mathrm{kHz}$ \\
\hline $250 \mathrm{~V}$ & $183 \mathrm{kHz}$ & $185 \mathrm{kHz}$ \\
\hline
\end{tabular}

The simulated waveforms for constant $2700 \mathrm{~W}$ output power is given in Fig. 7-Fig.9. Fig. 7 shows the waveforms of $\mathrm{v}_{\mathrm{Cr}}, \mathrm{i}_{\mathrm{Lr}}$ and $\mathrm{v}_{\mathrm{ab}}$ with $450 \mathrm{~V}$ output voltage at $109.8 \mathrm{kHz}$ switching frequency. In Fig. 8, same waveforms are given for $350 \mathrm{~V}$ output voltage at $126 \mathrm{kHz}$. Fig. 9 gives the same waveforms for $250 \mathrm{~V}$ output voltage at $185 \mathrm{kHz}$. According to obtained results from simulation study LLC resonant converter works with fundamental principles.

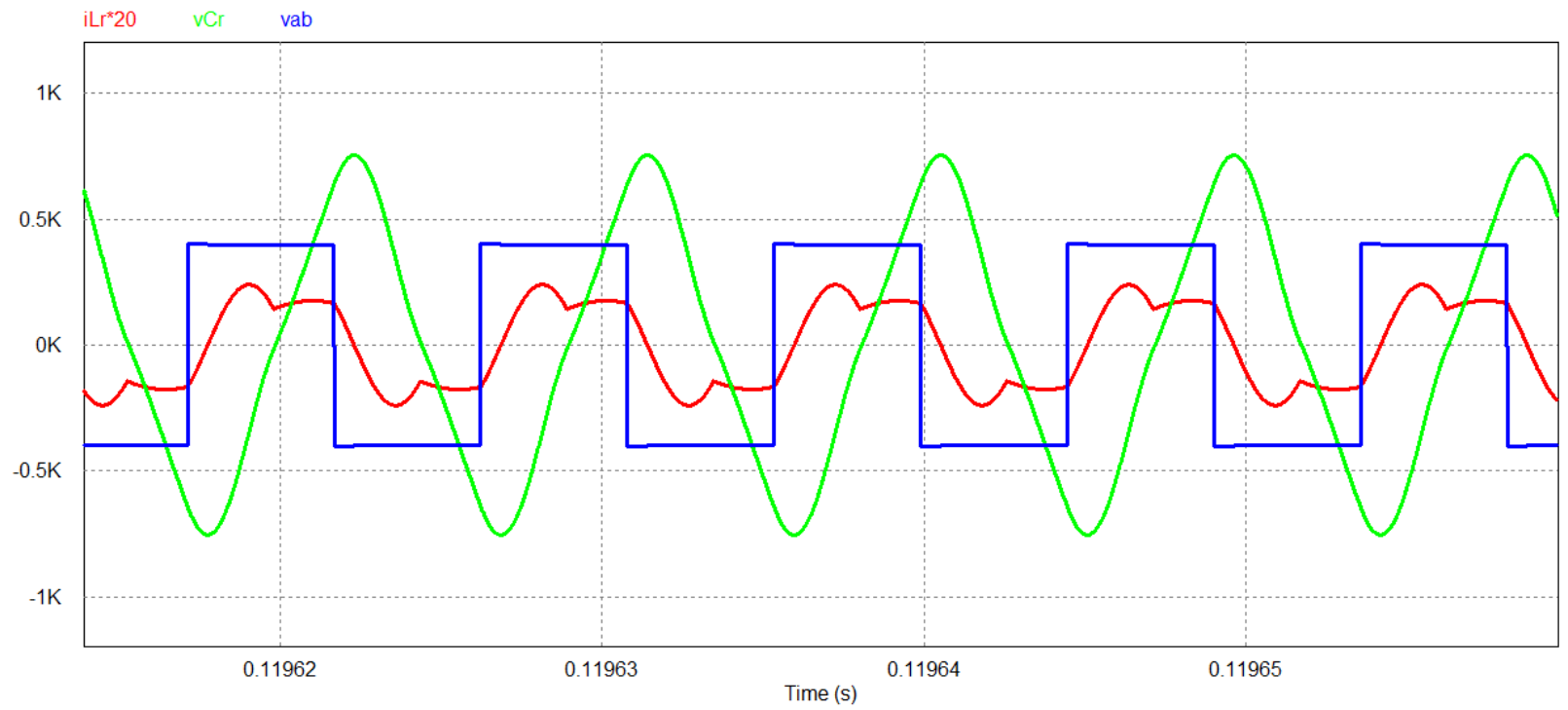

Fig. 7. Simulated waveforms of LLC resonant converter with $2700 \mathrm{~W}$ output power and $450 \mathrm{~V}$ output voltage at $109.8 \mathrm{kHz}$ switching frequency. 


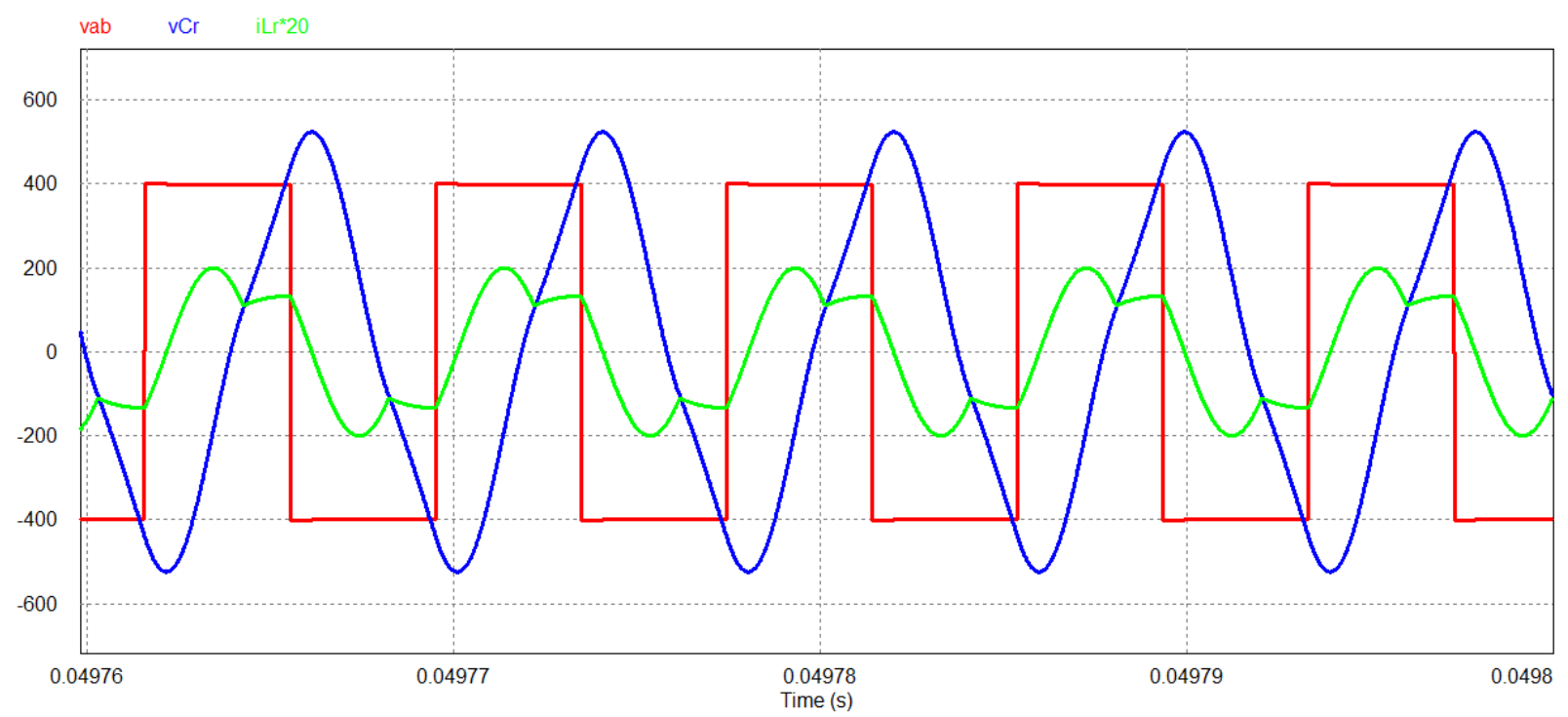

Fig. 8. Simulated waveforms of LLC resonant converter with $2700 \mathrm{~W}$ output power and $350 \mathrm{~V}$ output voltage at 126

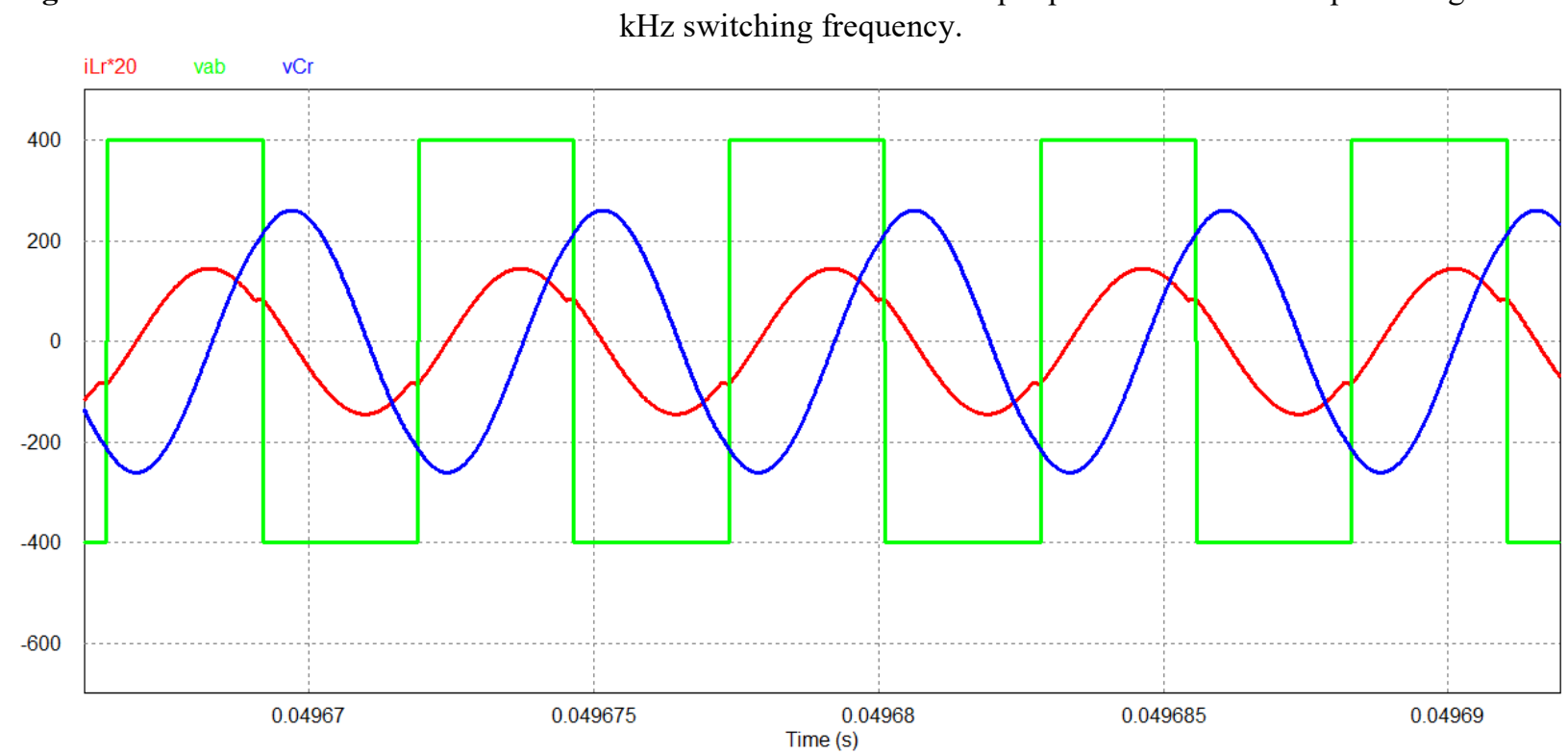

Fig. 9. Simulated waveforms of LLC resonant converter with $2700 \mathrm{~W}$ output power and $250 \mathrm{~V}$ output voltage at 183 $\mathrm{kHz}$ switching frequency.

\section{Conclusions}

In this study, the accurate voltage gain of the LLC resonant converter is discussed. The time domain analysis and FHA methods are used to obtain accurate results. A simulation study is performed with 2700 output power and $250 \mathrm{~V}-450 \mathrm{~V}$ output voltage range. Finally, analytical gain results are compared with the simulation results. According to compared results, the analytical voltage gain of LLC resonant converter is in good match with simulation results. The simulated waveforms also validate the fundamental principles of the converter. 


\section{Acknowledgment}

This work is supported by TUBITAK under grant number 116E125.

The attendance costs of symposium are supported by Pamukkale University Scientific Research Coordination Unit, ADEP/2018 - 2018KRM002-185.

\section{References}

[1] [1] B. Whitaker, A. Barkley, Z. Cole, B. Passmore, D. Martin, T.R. McNutt, A.B. Lostetter, J.S. Lee, K. Shiozaki, "A high-density, high-efficiency, isolated on-board vehicle battery charger utilizing silicon carbide power devices," IEEE Transactions on Power Electronics, vol. 29, pp. 2606-2617, January 2014.

[2] [2] M. Yilmaz, P.T. Krein, "Review of battery charger topologies, charging power levels, and infrastructure for plug-in electric and hybrid vehicles," IEEE Transactions on Power Electronics, vol. 28, pp. 2151-2169, May 2013.

[3] [3] M. Grenier, M.H. Aghdam, T. Thiringer, "Design of on-board charger for plug-in hybrid electric vehicle," In Proc. Power Electronics, Machine and Drives, Brighton, England, 19-21 April 2010.

[4] [4] S. Haghbin, K. Khan, S. Lundmark, M. Alakula, O. Carlson, M. Leksell, O. Wallmark, "Integrated chargers for EV's and PHEV's: examples and new solutions," In Proc. Int. Conf. Electrical Machines, Rome, Italy, 6-8 September 2010.

[5] [5] A. Emadi, Y.J. Lee, K. Rajashekara, "Power electronics and motor drives in electric, hybrid electric, and plug-in hybrid electric vehicles," IEEE Trans. Ind. Appl., vol. 55, pp. 2237-2245, June 2008.

[6] [6] A. Emadi, S.S. Williamson, A. Khaligh, "Power electronics intensive solutions for advanced electric, hybrid electric, and fuel cell vehicular power systems," IEEE Trans. Power Electronics, vol. 21, pp. 567-577, May 2006.

[7] [7] M. Chen, G.A. Rinc' on-Mora, "Accurate, compact and power-efficient li-ion battery charger circuit," IEEE Trans. Circuits Syst. II, Exp. Briefs, vol. 53, pp. 1180-1184, November 2006.

[8] [8] S. Dearborn, "Charging li-ion batteries for maximum run times," Power Electron. Technol. Mag. vol. 31, pp. 40-49, April 2005.

[9] [9] F. Musavi, M. Craciun, D.S. Gautam, W. Eberle, W.A. Dunford, "An LLC resonant DC-DC converter for wide output voltage range battery charging applications," IEEE Trans. on Power Electronics, vol. 28, pp. 5437-5445, March 2013.

[10] [10] J. Deng, S. Li, S. Hu, C.C Mi, R. Ma, "Design methodology of LLC resonant converters for electric vehicle battery chargers," IEEE Trans. On Vehicular Technology, vol. 63, pp. 1581-1592, May 2014.

[11] [11] Z. Fang, T. Cai, S. Duan, C. Chen, "Optimal design methodology for LLC resonant converter in battery charging applications based on time-weighted average efficiency," IEEE Trans. On Power Electronics, vol. 30, pp.5469-5483, May 2015.

[12] [12] L. R. Steigerwald, "A comparison of half bridge resonant converter topologies," IEEE Trans. on Power Electronics, vol.3, pp. 174-182, April 1988.

[13] [13] B. Lu, W. Liu, Y. Liang, F.C. Lee, J. D. van Wyk,, "Optimal design methodology for 
LLC resonant converter," In Proc. Applied Power Electronics Conference and Exposition APEC '06, Dallas, USA, 19-23 March 2006.

[14] [14] Y. Fang, D. Xu, Y. Zhang, F. Gao, L. Zhu, "Design of high power density LLC resonant converter with extra wide input range," In Proc. Applied Power Electronics Conference and Exposition APEC '07, Anaheim, USA, 25 Feb.-1 Mar 2007.

[15] [15] D. Huang, D. Gilham, W. Feng, P. Kong, D. Fu, F. C. Lee, "High power density high efficiency DC-DC converter," In Proceeding of Energy Conversion Congress and Exposition (ECCE), Phoenix, USA, 17-22 Sep 2011.

[16] [16] J. Biela, U. Badstuebner, J. W. Kolar, "Design of a 5-kW, 1-U, 10-kW/dm3 resonant DC-DC converter for telecom applications," IEEE Trans. on Power Electronics, vol. 24, pp. 1701-1710, July 2009.

[17] [17] S. D. Simone, C. Adragna, C. Spini, G. Gattavari, "Design-oriented steady state analysis of LLC resonant converters based on FHA," In Proc. International Symposium on Power Electronics, Electrical Drives, Automation and Motion SPEEDAM, Taormina, Italy, 23-26 May 2006.

[18] [18] J. F. Lazar, R. Martinelli, "Steady-state analysis of the LLC series resonant converter," In Proc. Applied Power Electronics Conference and Exposition APEC '01, Anaheim, USA, 4-8 Mar 2001.

[19] [19] R. Yu, G.K.Y. Ho, B. M. H. Pong, B. W. K. Ling, J. Lam, “Computer aided design and optimization of high efficiency LLC series resonant converter," IEEE Trans. Power Electronics, vol. 27, pp. 3243-3256, April 2012.

[20] [20] Navid Shafiei, Mohammad Ali Saket, and Martin Ordonez, "Time Domain Analysis of LLC Resonant Converters in the Boost Mode for Battery Charger Applications, Energy Conversion Congress and Exposition (ECCE), pp. 1-6, 1-5 October 2017, Cincinnati, OH, USA. 